\title{
The Rise of Human Service Chains: Antecedents to Acquisitions and Their Effects on the Quality of Care in US Nursing Homes
}

\author{
Jane Banaszak-Holl ${ }^{\mathrm{a}}$, Whitney B. Berta ${ }^{\mathrm{b}}$, Dilys M. Bowman ${ }^{\mathrm{c}}$, \\ Joel A.C. Baum ${ }^{\mathrm{d}}$ and Will Mitchell ${ }^{\mathrm{e}, *}$ \\ ${ }^{a}$ Department of Health Management and Policy, School of Public Health, University of Michigan, \\ Ann Arbor, MI, USA \\ ${ }^{\mathrm{b}}$ Department of Health Administration, University of Toronto, Toronto, Ont., Canada \\ ${ }^{\mathrm{c}}$ Department of Health Behavior and Health Education, School of Public Health, University of Michigan, \\ Ann Arbor, MI, USA \\ ${ }^{\mathrm{d}}$ Rotman School of Management, University of Toronto, Toronto, Ont., Canada \\ ${ }^{\mathrm{e}}$ The Fuqua School of Business, Duke University, Durham, NC, USA
}

\begin{abstract}
This paper studies acquisitions of nursing home facilities by chains. We first test alternative 'cream-skimming' and 'turn-around' arguments concerning nursing home acquisitions. We then consider post-acquisition changes in nursing home health performance, differentiating effects of the acquisition process from those of prior strategy and performance of the acquired home and acquiring chain. Our dynamic empirical analysis of more than 5000 acquisitions by US nursing home chains from 1991 through 1997 shows that nursing home chain acquisitions are driven by a turn around logic, and that performance depends on the prior quality of the target and acquirer. Our analysis is relevant to policy on the nursing home sector, helping clarify why certain homes are acquired and how being acquired affects their residents' welfare. At a more general level, we offer insights concerning strategic factors that promote acquisition and drive expansion of service sector chains. Copyright (C) 2002 John Wiley \& Sons, Ltd.
\end{abstract}

\section{INTRODUCTION}

Chains of multiunit organizations are emerging as the dominant organizational form across a diverse array of service industries, including health care, hotels, banking, auto services, food services, and business services (Greve and Baum, 2001). A chain is a collection of similar organizations, linked together into a larger 'super-organization,' that do essentially the same thing (Ingram and Baum, 1997). Much of the increase in chaining is

\footnotetext{
*Correspondence to: The Fuqua School of Business Duke University, Box 91020, Durham, NC 27708-0120, USA.
}

occurring via acquisitions of facilities, either from independence or from other chains. Standardization is the strategic ethos of chain organizations, offering the benefits of scale economies and reputation through brand-name recognition (Ingram, 1996). As a result, chains tend to change the operating activities of acquired components, to bring them in line with overall chain procedures (Karim and Mitchell, 2000). While the realization of the benefits of standardization have been applauded in some industries as affording increases in productivity as well as consistency in output quality and reliability (see Argote and Ingram, 2000), standardization is the subject of concern in other industries. 
In the long-term care industry of the health services sector, in particular, the growth of nursing home chains through acquisitions has led to concerns expressed over resident welfare, because operating cost reductions achieved through standardization might reduce the quality of health-care services that nursing homes provide for their residents. Media attention has focused on prominent quality problems in some chains (Consumer Reports, 1995; McGinley, 1999), while recent academic research raises similar concerns (Harrington et al., 2001). Social theorists argue that health-care chains pursue corporate interests over patient needs (Light, 1986) and, in doing so, introduce bureaucracy and impersonality into an already distrustful relationship between provider and consumer (Scott et al., 1995; Starr, 1982). No large-scale empirical research, though, has examined the impact of acquisitions on nursing home resident welfare.

The study has both industry-specific and general implications. The industry-specific implications apply to the driving forces and impact of chaining on health sector service quality. More generally, the study contributes to our understanding of multiunit chains in a variety of sectors whose performance depends on the transfer of administrative routines and capabilities among units. Thus, our findings may generalize to hotel, restaurant and retail chains, as well as multibranch banks, which have incentives to standardize their operating practices and may, as a consequence, reduce some types of services of acquired units while improving others. We will return to the more general issues as we develop the core arguments of the paper.

Research on nursing homes and other healthcare providers provides several explanations for corporate acquisitions and suggests several possible consequences for health performance. Acquisitions provide a way to fund improvements in the face of government payment systems that cap reimbursements, limit bed supply, and constrain profit margins (Baum, 1999; Light, 1986). Acquisitions also provide an opportunity for chains to transfer, replicate, and profit from effective capabilities and skills they have developed (Baum et al., 2000; Mitchell et al., 2002). As a result, the availability of new capital and capabilities might lead to better care at acquired homes. On the other hand, chain operators may be more willing than independent homes to undertake cost-cutting, which has led to charges that chains under-invest in facilities, staff, and innovation (Aaronson et al., 1994; Banaszak-Holl et al., 1996; Rosko et al., 1995; Weisbrod and Schlesinger, 1986). Supporting the cost-cutting characterization, studies have shown that for profit nursing homes provide fewer services (Lemke and Moos, 1989) and maintain lower staffing ratios (Aaronson et al., 1994; Nyman and Bricker, 1989). Consistent with these studies, Harrington et al. (2001) found that chain ownership was associated with poorer quality care. Cohen and Dubay (1990), however, found that chain nursing homes reported lower costs, but without harming service quality. Available studies of acquisitions in other health-care sectors, such as multihospital chains, yield mixed evidence on the financial impact of acquisitions in those sectors (Dranove and Shanley, 1995; Dranove et al., 1996; Tennyson and Fottler, 2000).

In addition to immediate financial objectives, other strategic factors may drive chain expansion. Poor quality nursing homes may become available for acquisition, either to avoid state censuring of poor quality care or to gain skills needed to improve services. Chains may respond to pressures from managed care firms to provide broader sets of services within integrated organizations (Zinn et al., 1999). In addition, chains may seek market power relative to other health-care providers, which also are consolidating (Wells and BanaszakHoll, 2000).

We address several gaps in the research on nursing home chain acquisitions. While chain ownership is widely held to affect the quality of nursing home care, few studies examine both causes and consequences of nursing home acquisitions. We do not know whether chains tend to target poor quality or high-quality facilities for acquisition nor what impact acquisition has on health performance. Research to date has focused primarily on financial performance, rather than on changes in health performance and, for nursing homes in particular, typically assesses ownership effects using a simple chain versus non-chain facility dichotomy (Baum, 1999). Equivocal findings (e.g., Cohen and Dubay, 1990; Holmes, 1996; Lee et al., 1983) may be the result of failing to distinguish the effects of acquisitions by chains with different characteristics. Given trends toward increased chain ownership, and the corresponding rhetoric concerning chain management, we need better understanding of forces promoting nursing home acquisition and 
better measurement of chain characteristics when examining acquisition consequences.

\section{HYPOTHESES}

\section{Predictors of Nursing Home Acquisition}

We consider two incentives for chains to undertake acquisitions, differentiating between 'turnaround' and 'cream-skimming' strategies. Recent research in corporate strategy views acquisitions as means by which firms undertake strategic change -a mechanism through which organizations change, reconfigure, and/or redeploy capabilities that firms cannot easily exchange on the open market (Barney, 1991; Huber, 1991; Peteraf, 1993; Szulanski, 1996; Capron et al., 1998). Changefocused acquisitions also provide opportunities to gain scale, reduce costs, and increase competitiveness (Jensen, 1986; Dutz, 1989; Chatterjee and Wernerfelt, 1991). In this view, acquiring chains will often target poor performing homes, with the intention of changing management, shifting strategy, and infusing the targets with new ideas and technology (Ingram and Baum, 2001; Penrose, 1959; Mitchell, 1994; Karim and Mitchell, 2000). Under this turn-around scenario, chains attempt to improve on the pre-acquisition performance of targeted homes, especially under-performing targets, using their greater management skill (Jensen and Ruback, 1983; Wernerfelt, 1984).

Alternatively, acquisitions may involve takeovers of high-performing targets. Under this 'cream-skimming' scenario, chains use acquisitions as a mechanism for adding to a reputation for quality, gaining effective market access, and reducing competition (Mueller, 1980; Scherer and Ross, 1990; Pfeffer and Salancik, 1978). With the 'cream-skimming' scenario, post-acquisition performance of a target may decline because there is little room for improvement in a high-quality facility's performance and the chain may be unable or unwilling to invest sufficient resources to sustain the facility's prior high performance (e.g., Ravenscraft and Scherer, 1987).

The first hypothesis articulates the turn-around and cream-skimming alternatives.

\section{H1:}

The poorer (better) a nursing home's health performance, the more likely a chain will acquire the home.
To foreshadow the analysis, we will test for nonlinear effects of nursing home health performance on acquisition likelihood. If both turnaround and cream-skimming motives apply, then chains might tend to acquire targets at performance extremes (i.e., both high- and low-quality facilities). Alternatively, even if the turn-around tendency dominates, chains might acquire homes with mediocre performance, but avoid facilities with very poor performance.

In addition to considering the quality of a potential acquisition target, chains also will consider other characteristics of facilities and the competitive context in which they operate. The empirical models control for factors including facility-level characteristics that may affect the attractiveness of particular targets, chain characteristics that may affect the acquisitiveness of particular chains, as well as environmental factors including local market competition and demand, state regulations and payment policies, and regional influences.

\section{Consequences of Acquisition}

Chain and other multiunit organizations have been found to enhance performance through interunit knowledge transfer in manufacturing (Epple et al., 1996; Karim and Mitchell, 2000) and service (Darr et al., 1995; Baum and Ingram, 1998) sectors. Chains may transfer skills as R\&D capabilities, production know-how, use of specific technologies, applications of new products, marketing skills, management of supplier and regulatory relations, management of distribution channels, and administrative procedures. Any of these skills can be standardized across chain components, in nursing homes and in other service sectors. Such transfers may or may not involve physical movement of resources to new locations.

The positive value of resource transfers to newly acquired facilities may, however, be offset by the negative consequences of transfer. Corporate managers who are over-confident in their own capabilities may force adoption of inappropriate practices (Greve, 1999; Ingram and Baum, 1997). In addition, skill transfers intended to improve one activity, such as cost efficiencies, may harm activities in other areas, such as resident care in nursing homes or service quality more generally in other sectors. 
Acquisition consequences, independent of target and acquirer performance. The acquisition process is a disruptive organizational change (Hannan and Freeman, 1984). As such, acquisition might harm target performance in the short run, even if followed by later improvements. Acquisitions can harm target performance by redefining communication lines and role relationships, disrupting work groups, and requiring the learning and use of new or altered operating practices. In nursing homes, such disruptions can result in declines in health performance. Any such problems will tend to emerge soon after acquisition, as acquirers begin to undertake changes.

\section{H2:}

Acquisitions will cause short-term declines in health performance at acquired nursing homes.

Acquisition consequences, conditioned by target and acquirer performance. We expect the longer-term impact on health performance to depend on the previous health quality of the target and acquirer. First, consider how a target's performance will affect post-acquisition change. Chains that acquire low-performing targets may promote improved target performance over time as operating improvements take hold and facilities achieve the benefits of the chain's scale economies (Capron, 1999). Conversely, in previously high-performing facilities, the chain organization can do little to improve performance and the chain may be unable or unwilling to invest sufficient resources to sustain the facility's high performance (e.g., Ravenscraft and Scherer, 1987). Attempts to transfer capabilities may force a target facility to adopt inferior and/or inappropriate capabilities. Moreover, cutting a home's resources in the process of cost reduction and standardization may lower service quality and health performance, or may perturb the very processes and relationships that contributed to high performance in the first place. For example, a chain may impose standardized guidelines for treating health problems that are effective at reducing costs but do not fit the specific needs of a facility's resident population.

\section{H3:}

The poorer (better) a target home's health performance, the greater the post-acquisition improvement (decline) in health performance at the target.

Second, consider the impact of chain performance on changes in target performance. As we noted above, chains tend to affect the capabilities and performance of acquired units through standardization. Standardization of services, advertising, administration, operating procedures, equipment, and even buildings raises consumers' perceptions of a chain's reliability (Ingram, 1996; Baum, 1999), while interdependence puts pressure on facilities to maintain and enhance the chain's standards (Ingram, 1996). Standardization results in convergence between the capabilities of a chain and the targets it acquires (Baum et al., 2000; Mitchell et al., 2002). As convergence occurs, quality will improve most for targets acquired by high-quality chains.

We expect acquisitions to result in post-acquisition health performance improvements at the target if the acquiring chain possesses superior capabilities that it can transfer to the target. Thus, a chain's ability to improve a target's operating strategy and health performance depends on the performance characteristics of both the target and its acquirer (Capron and Mitchell, 1998).

\section{H4:}

The better (poorer) a chain's health performance, the greater the post-acquisition improvement (decline) in health performance at the target.

As in our analysis of acquisition likelihood, we will control for other target and environmental factors that might influence post-acquisition performance. We will also assess the impact of other chain characteristics.

In sum, the predictions relate a target's performance to the likelihood it will be acquired and, in turn, how chain and target performance affect post-acquisition health performance. First, we want to establish whether chains target high- or low-performing homes for acquisition. Then we expect short-term post-acquisition disruptions, followed by changes in acquired facility performance that depend on the prior performance of the target and the chain. Our findings will help to clarify why certain homes are acquired and how being acquired affects their residents' welfare. 


\section{DATA AND METHODS}

\section{Data}

The level of analysis for the study is the individual nursing home facility. We use a longitudinal data set of information concerning nursing home facilities that links the annual files of the federal On-line Survey Certification and Reporting System (OSCAR) data. The OSCAR files include information from state-based inspections of all Medicare/Medicaid certified nursing homes operating in the 48 continental US states from 1991 to 1997. OSCAR includes facility-level information on nursing home structure (e.g., size, staffing, services offered), resident case mix (e.g., the proportion of residents requiring assistance with Activities of Daily Living and who are incontinent), system membership (e.g., multiunit organization affiliation and name), and counts of deficiencies reported during state inspections. Inspections are mandated on an annual basis, although the time between inspections can be 2 years or more (the mean inspection period in our data is 374 days). We also use the Area Resource File, as well as data available through the website maintained by the US Health Care Financing Administration (HCFA), including the annual State Data Books on Long Term Care Programs and Market Characteristics produced for HCFA (Harrington et al., 1999), and other sources to obtain control variables for market and state characteristics.

Key to our analysis is the operationalization of chain membership. About half the nursing homes in these data report belonging to a multiinstitution corporation; this is the variable that traditionally identifies chain membership for nursing home studies. The OSCAR data also include the names of the multiinstitutional corporations to which nursing homes reported belonging. Departing from past research, we identified nursing home chains and nursing homes' membership in these chains based on corporate names. Identifying the chains was necessary in order to study the effects of differential chain characteristics on target performance. We coded this variable through line-by-line inspection of the records (more than 100000 records) and assessed inconsistencies by comparing the spelling of names, and intertemporal relationships to specific homes. Finally, we checked corporate ownership for large chains using the 1990-1998 volumes of the Medical and
Healthcare Marketplace Guide (Dorland's Biomedical Publications).

We found that about $7 \%$ of nursing homes reported belonging to a multiunit company but were the only facilities reporting ownership by their corporations. We labeled such cases 'singlehome holding companies,' some of which are standalone companies and some of which are part of health provider systems that include facilities other than nursing homes (e.g., continuing care retirement communities, hospitals, or health systems). Failure to identify single-home 'chains' in research relying on reports of membership in multiunit institutions may affect previous findings. In our analyses, we define chains as corporations that own at least two facilities in a given calendar year (i.e., we do not code single-home holding companies as chains).

Table 1 reports the number of nursing home facilities and chains from January 1991 through September 1997. In total, there are about 104000 records in the data set, covering over 19000 unique nursing homes. ${ }^{1}$ We identified 2255 unique nursing home chains. Most of the multi-home chains are small, with roughly $87 \%$ operating 10 or fewer homes. Thus, extensive chaining of nursing homes exists, but it is still primarily a small-scale phenomenon.

\section{Measures}

Appendix A describes the variables and provide descriptive statistics. We eliminated outliers on nursing home size and staffing intensity variables because these extreme cases (e.g., several facilities reported a staffing to resident ratio of greater than 10:1) likely have other measurement problems. Where appropriate, we lagged the independent variables by one period relative to the dependent variables.

Independent variables. Acquisition. Acquisition is the dependent variable in the first set of analyses and the key in dependent variable in analyses of changes in health performance. We record acquisitions - about 5000 in number-as cases in which the reported name of the corporate owner for a nursing home facility changed between inspections. This variable is the dependent variable for the acquisition likelihood analysis. As independent variables in the analyses of changes in health performance, we defined a set of four dummy 
Table 1. Descriptive data on the number of nursing homes and chains of nursing homes operating in the United States from January, 1991 through September, 1997

\begin{tabular}{|c|c|c|c|c|c|c|c|c|c|}
\hline & Total & 1991 & 1992 & 1993 & 1994 & 1995 & 1996 & $\begin{array}{l}1997 \\
(9 \mathrm{mon})\end{array}$ & $\begin{array}{l}\text { 1991-1996 } \\
\text { mean }\end{array}$ \\
\hline $\begin{array}{l}\text { Total nursing home records, } \\
\text { by year }\end{array}$ & 103949 & 13467 & 15682 & 15927 & 15605 & 14831 & 17755 & 10682 & 15545 \\
\hline Unique nursing homes & 19558 & & & & & & & & \\
\hline $\begin{array}{l}\text { Independent nursing homes } \\
\text { (no corporate parent) }\end{array}$ & 52501 & 7289 & 8059 & 8057 & 7752 & 7115 & 8954 & 5275 & 7871 \\
\hline $\begin{array}{l}\text { Nursing homes operated by } \\
\text { single-home holding } \\
\text { companies }\end{array}$ & 7059 & 865 & 1216 & 1025 & 1076 & 1033 & 1207 & 637 & 1070 \\
\hline $\begin{array}{l}\text { Nursing homes operated by } \\
\text { chains (own } 2+\text { homes) }\end{array}$ & 44389 & 5313 & 6407 & 6845 & 6777 & 6683 & 7594 & 4770 & 6603 \\
\hline Total nursing home records & 103949 & 13467 & 15682 & 15927 & 15605 & 14831 & 17755 & 10682 & \\
\hline $\begin{array}{l}\text { Independent nursing homes } \\
\text { ( } \% \text { of total homes })\end{array}$ & & $54 \%$ & $51 \%$ & $51 \%$ & $50 \%$ & $48 \%$ & $50 \%$ & $49 \%$ & $51 \%$ \\
\hline $\begin{array}{l}\text { Single-home holding companies } \\
\text { ( } \% \text { of total homes) }\end{array}$ & & $6 \%$ & $8 \%$ & $6 \%$ & $7 \%$ & $7 \%$ & $7 \%$ & $6 \%$ & $7 \%$ \\
\hline $\begin{array}{l}\text { Nursing homes operated by } \\
\text { chains ( } \% \text { of total homes) }\end{array}$ & & $39 \%$ & $41 \%$ & $43 \%$ & $43 \%$ & $45 \%$ & $43 \%$ & $45 \%$ & $42 \%$ \\
\hline Total & & $100 \%$ & $100 \%$ & $100 \%$ & $100 \%$ & $100 \%$ & $100 \%$ & $100 \%$ & \\
\hline $\begin{array}{l}\text { Number of unique chains } \\
\text { (own } 2+\text { homes) }\end{array}$ & 2255 & 725 & 863 & 872 & 880 & 858 & 928 & 624 & 854 \\
\hline Operate $2-10$ homes & & $89 \%$ & $86 \%$ & $87 \%$ & $87 \%$ & $87 \%$ & $86 \%$ & $89 \%$ & $87 \%$ \\
\hline Operate 11-50 homes & & $10 \%$ & $13 \%$ & $11 \%$ & $10 \%$ & $11 \%$ & $11 \%$ & $8 \%$ & $11 \%$ \\
\hline Operate $51+$ homes & & $1.7 \%$ & $1.4 \%$ & $1.5 \%$ & $2.2 \%$ & $2.2 \%$ & $2.3 \%$ & $2.6 \%$ & $2 \%$ \\
\hline Total & & $100 \%$ & $100 \%$ & $100 \%$ & $100 \%$ & $100 \%$ & $100 \%$ & $100 \%$ & \\
\hline
\end{tabular}

variables indicating the number of inspection periods since an acquisition (with the last period equal to four or more periods since acquisition; inspection periods average one year).

The study limits acquisitions to those cases in which the new corporate owner operated at least two nursing home facilities during the calendar year of the inspection that reported the new ownership. The analyses also include a dummy variable that controls for other ownership change, identifying cases in which the new owner is a single-home holding company. Thus, we examine whether ownership changes in general affect facilities' health performance; we expect that the effect of chain acquisition will be stronger than simply changing owners of a facility.

Nursing home health performance. Nursing home health performance is central to the analyses as a predictor of the likelihood of acquisition and as a dependent variable in the analyses of changes in target performance. We measure health performance in two ways - citations of health deficiencies on state inspections and percentage of residents with pressure ulcers - to assess different aspects of a nursing home's quality of care. Previous research uses both measures to indicate nursing home quality (e.g., Marlin et al., 1999; Mukamel, 1997).

Nursing homes receive health deficiency citations during annual inspections for problems that threaten resident health. This measure indicates quality problems for which the facility is being publicly sanctioned, potentially damaging the public reputation of the home as well as the health of the residents. We scale each facility's number of deficiencies by the mean for all facilities in the state, so that the deficiency measure centers near a value of about 1.0 , because previous research has found substantial state variation in citations (Harrington and Carillo, 1999).

Pressure ulcers or skin ulcers commonly develop when nursing home residents are neglected. Pressure ulcers are preventable and treatable and so provide good indicators of care quality (Aaronson et al., 1994). The percentage of residents with pressure ulcers indicates a health-care quality 
problem directly linked to a resident's quality of life in a facility.

In the analysis of acquisition likelihood, we include squared terms of the quality measures in addition to the main effects. The nonlinear specification will be significant if chains tend to acquire targets with extreme values of health quality (negative main effect, positive squared term) or if they tend to purchase mediocre targets while avoiding targets at the extreme of poor performance (positive main effect, negative squared term).

Chain health performance. Measures of chain level performance are critical to our argument that chain characteristics influence facility level postacquisition performance. We created two chainlevel performance variables analogous to those for the nursing home level by aggregating information on the number of state-weighted deficiencies and percentage of residents with pressure ulcers for all nursing homes belonging to a chain and then using the mean values of the measures by chain year. Thus, we measure a chain's health performance as the mean number of health deficiencies and mean proportion of residents with pressure ulcers across the chain's member facilities (chain-level measures omit the focal facility from chain means).

Interactions. As we describe in more detail below in the analysis section, we specify several interactions of acquisition with target and acquirer health performance (e.g., acquisition $\times$ target health deficiencies). We use these interactions to test our predictions ( $\mathrm{H} 3$ and $\mathrm{H} 4)$ about the effects of target and acquirer performance on post-acquisition target performance.

Control variables. The analyses include multiple controls. We examine other nursing home characteristics, other ownership changes, time periods, other chain characteristics, and market characteristics. Table A2 defines each of the variables.

Nursing home characteristics. In addition to our main theoretical variables of interest, we include time-varying controls for several nursing home characteristics that may affect their attractiveness for acquisition and performance. We measure each nursing home's total beds, capacity utilization, hospital affiliation, chain affiliation, and ownership type (non-profit, government, or for-profit).

We also control for facility operating strategy, using five measures. Two measures denote the prevalence of two types of specialty service beds, for residents with Alzheimer's disease and for residents with rehabilitative needs. One measure records the extent to which residents receive specialty-care services (injections, physiotherapy, ostomy, respiratory, suction, IV therapy, or tracheotomy). The other two measures denote staffing intensity, which is the ratio of total staff to the number of residents in the facility, and record Registered Nurses as a proportion of total care staff.

These measures address several aspects of facility strategy. The availability of specialty beds for nursing home residents is important because these beds represent service innovations driven by changing regulations, technology, and policy concerning long-term care (Banaszak-Holl et al., 1996). The Alzheimer's and rehabilitation specialty services differ significantly from more standard nursing-care services because they treat resident needs that require additional skills, greater staff training, and more extensive medical equipment. While specialty beds may incur higher costs than general care beds, they may also generate higher revenues and reduce medical complications. The availability of specialty services denotes a facility's investment in complementary activities. Staffing is a nursing home's largest operating expense, and the number of staff that a home employs has a major influence on costs (Zinn, 1993). The measure of staffing intensity includes FTEs of all nursing and ancillary employees (this measure correlates highly with nursing-specific staffing measures). The proportion of Registered Nurses (RNs) within total care staff (RNs, LPNs, and aides) denotes a facility's emphasis on professional, higher cost care.

Specialty services and staffing intensity are affected by resident case mix, and the mix of payment sources for resident care. To control for resident case mix, we include the proportion of residents who were restrained, incontinent, bedfast and/or receiving anti-psychotic drugs. We control for payer mix by identifying different payment sources (Medicare, Medicaid, or private pay). In addition, because some nursing homes manipulate case mix in response to the Medicaid reimbursement structure in use in a given state (Cohen and Dubay, 1990), we control for state-level reimbursement policies, as we describe below.

Other ownership changes and time periods. Two sets of variables address other ownership changes and time periods. First, two variables examine 
other ownership change issues. As noted earlier, we identify cases of ownership change that do not involve chains (i.e., acquisition by a single-home holding company) and use a dummy variable to control for their occurrence. To control for the possibility that chains sometimes buy facilities and then quickly resell some or all of the acquired homes, we include a control for whether a chainowned facility was acquired by its chain owner within the past two inspection periods in the acquisition models. Second, to control for time period effects, we include controls for the calendar year in which the nursing home's inspection occurs, as well as the number of days between its inspections.

Chain characteristics. We also control for a set of variables reflecting chain characteristics that may affect their acquisitiveness and performance. These include for-profit ownership and chain size (number of homes), as well as chain level operating strategy controls for mean staff intensity, proportion of Alzheimer's beds, and proportion of rehabilitation care beds across the facilities that belong to a chain in a given year (omitting the focal home).

Market, state and regional characteristics. Consistent with common practice, we use the county as the market level. Market controls include the total nursing home beds per capita, market concentration of nursing home beds measured with the Hirschman-Herfindahl Index (HHI is the sum of squared shares of beds of all nursing homes in the county), and the number of nursing homes. We also record a nine-value code for the rural-urban status of the county (using the rural/urban continuum in the Area Resource File).

We define controls at the state and regional level. State-level reimbursement measures include the mean Medicaid reimbursement rate across this period, the mean Medicaid expenditures per recipient, and the mean Medicare expenditures per recipient. State-level expansion controls include whether the state has a Certificate of Need and/or construction moratoria that limit new nursing home construction (Harrington et al., 1999). Because the Medicare/Medicaid programs are key payers for nursing home care and other state regulation has significantly affected nursing home chains' ability to build new beds in markets, these factors may have significant effects on the chain's decision to acquire a facility and may also influence post-acquisition strategy. At the regional level, we include dummy variables for eight geographic areas, including the New England, Mid-Atlantic, Great Lakes, Prairie, Southeast, Southwest, Rocky Mountain and Far-west regions. Table A2 lists the states in each region.

\section{Statistical Analysis}

We employ two estimation techniques. The first estimates the likelihood of acquisition. The second estimates how acquisition influences health quality change at a facility.

We use logistic regression in one-period spells to estimate the likelihood that a given nursing home will be acquired (one period is the time between inspections, which averages about a year). The independent variables include the characteristics of the individual nursing facilities and market and state level controls. The count of acquisitions includes acquisitions of both freestanding and already chain-owned facilities (a chain-owned facility may be acquired if the chain is acquired by another chain or if an ongoing chain sells some of its facilities). ${ }^{2}$ It is possible that a chain that acquires a set of facilities from another chain (either by buying the entire chain or a subset of its facilities) might rapidly sell undesired facilities. To control this possibility, as we noted earlier, the analyses include a variable that indicates whether a facility was acquired during the two years prior to the current period.

The second model uses OLS techniques to analyze pooled cross-sectional data in order to estimate effects on changes in health performance (percent of residents with pressure ulcers and the state-averaged number of deficiencies received during state inspections). ${ }^{3}$ The representation of the OLS model, using change in health deficiencies as an example (which we label $Y_{i, t}$ for facility $i$ at time $t$ ), is as follows:

$$
\begin{aligned}
\left(Y_{i, t}-Y_{i, t-1}\right)= & \alpha+\pi_{1} A_{i, t-1}+\pi_{2}\left(A \times X^{\prime}\right)_{i, t-1} \\
& +\pi_{3}\left(A \times Z^{\prime}\right)_{i, t-1}+\beta Y_{t-1}+\delta X_{i, t-1} \\
& +\lambda Z_{i, t-1}+\gamma M_{i, t-1}+\rho R_{i, t-1}+\varepsilon_{i}
\end{aligned}
$$

The dependent variable $\left(Y_{i, t}-Y_{i, t-1}\right)$ is the change in health deficiencies between the survey completed at time $t-1$ and the survey completed at time $t$ for facility $i$. The independent variables are dummy variables indicating the number of periods (from 1 through 4 or more) since a facility 
was acquired $\left(A_{i, t-1}\right)$, the level of health deficiencies at the prior period $\left(Y_{t-1}\right)$, facility-level characteristics $\left(X_{i, t-1}\right)$, characteristics of the chain to which the facility belongs $\left(Z_{i, t-1}\right)$, the characteristics of the market $\left(M_{i, t-1}\right)$, other factors such as time and non-chain acquisition $\left(R_{i, t-1}\right)$ and a unique facility error term $\left(\varepsilon_{i}\right)$.

The model also contains two sets of interaction terms $\left(A \times X^{\prime}\right)$ and $\left(A \times Z^{\prime}\right)$. These are interactions of the acquisition variables $(A)$ with variables from the target characteristics vector $\left(X^{\prime}\right)$ and the acquirer characteristics vector $\left(Z^{\prime}\right)$. We define the interaction terms as follows:

$$
\begin{aligned}
\left(A \times X^{\prime}\right)_{i, t-1}= & A_{i, \text { per } 1} \times X_{i, t-1}^{\prime}, A_{i, \text { per } 2} \times X_{i, t-1}^{\prime}, A_{i, \text { per } 3} \\
& \times X_{i, t-1}^{\prime}, A_{i, \text { per } 4} \times X_{i, t-1}^{\prime}, \\
\left(A \times Z^{\prime}\right)_{i, t-1}= & A_{i, \text { per } 1} \times Z_{i, t-1}^{\prime}, A_{i, \text { per } 2} \times Z_{i, t-1}^{\prime}, A_{i, \text { per } 3} \\
& \times Z_{i, t-1}^{\prime}, A_{i, p e r} \times Z_{i, t-1}^{\prime} .
\end{aligned}
$$

The $X^{\prime}$ and $Z^{\prime}$ variables include the focal factors of target and acquirer performance that we want to investigate, as well as other control factors (size and for-profit status) that might shape the effects of acquisition. These interaction variables determine whether the effects of acquisition are contingent on the characteristics of the acquired home and/or the acquiring chain, as we expect. For facilities that have not been acquired or have never belonged to a chain, the variables in the $Z, A$, $\left(A \times X^{\prime}\right)$ and $\left(A \times Z^{\prime}\right)$ vectors equal zero.

The interaction terms between the period since acquisition $\left(A_{i, t-1}\right)$ and the characteristics of both the acquiring chain $\left(Z^{\prime}\right)$ and the target nursing home $\left(X^{\prime}\right)$ are critical to testing the hypotheses. These interaction terms estimate whether facilities and chains with specific characteristics are better able to effect changes in the health performance of a facility immediately following acquisition. For example, the interaction term between the first post-acquisition period and target performance takes the value of the target nursing home's performance during the first post-acquisition period, and set equal to 0 otherwise. In this way, we modify the main effects of acquisition to vary with the performance of the target facility and acquiring chain. By including four periods for each interaction, we can determine the temporal pattern of any effects.

\section{RESULTS}

\section{Likelihood of Acquisition}

Table 2 reports results for the logistic regression model predicting the likelihood of acquisition by a chain. This model tests $\mathrm{H} 1$ that the health performance of a facility will predict its likelihood of acquisition. The number of cases that we examine in Table 2 (83504) is smaller than the total sample (almost 104000 , in Table 1), because we lose cases from the one-period lag that is needed in order to examine potential acquisitions, as well as a small number of omitted cases owing to missing data and outliers for some variables as noted earlier.

We focus the discussion of Table 2 on the health quality question that arises in $\mathrm{H} 1$. The results are consistent with the 'turn-around' version of $\mathrm{H} 1$. Nursing homes cited for a greater number of health deficiencies during their most recent inspection and with a higher percentage of their residents experiencing pressure ulcers are significantly more likely to be acquired. In both cases, the main effects of the performance variables are positive, while the squared effects are moderately negative. The positive-negative pattern in the main and quadratic terms suggests that chains seek targets with poor performance, but may avoid homes that have extreme levels of health performance problems, likely because such homes represent too much of a turn-around challenge. ${ }^{4}$ (Models that omitted the squared terms produced highly significant positive coefficients for the main effects of both ulcer prevalence and health deficiencies.)

The results are both statistically and materially significant. For example, the log-odds indicate that, compared to a home with no health deficiencies, a facility with one deficiency (about the sample mean) is $7 \%$ more likely to be acquired, and a facility with two deficiencies (about one standard deviation above the mean) is $14 \%$ more likely to be acquired. Thus, facilities with poorer health performance among their residents are substantially more likely to be acquired by a chain. This is consistent with a turn-around view of acquisition incentives, in which firms purchase targets that offer improvement opportunities. In many cases, such targets will be available at relatively low prices, owing to their operating difficulties. 
Table 2. Logistic regression estimates of the likelihood of nursing home acquisition, 1991-1997

\begin{tabular}{|c|c|c|c|c|}
\hline \multicolumn{2}{|c|}{ ( positive coef. $=$ acquisition more likely) } & Coef. $^{\text {a }}$ & \multirow[t]{2}{*}{$p>t$} & Log-odd \\
\hline \multicolumn{4}{|c|}{ Facility health performance (H1) } & \\
\hline & Health deficiencies & 0.072 & 0.00 & 1.07 \\
\hline & Health deficiencies squared $(\times 100)$ & -0.495 & 0.04 & 0.61 \\
\hline & Resident ulcer prevalence & 1.046 & 0.00 & 2.85 \\
\hline & Ulcer prevalence squared & -0.690 & 0.09 & 0.50 \\
\hline \multicolumn{5}{|c|}{ Other facility-level characteristics } \\
\hline \multirow[t]{5}{*}{ Operating strategy } & Staff per resident & 0.061 & 0.15 & 1.06 \\
\hline & RNs per total care staff & 0.180 & 0.16 & 1.20 \\
\hline & Rehabilitation beds per total beds & -0.285 & 0.09 & 0.75 \\
\hline & Alzheimer's beds per total beds & 0.041 & 0.41 & 1.04 \\
\hline & Resident specialty services use prevalence & 0.079 & 0.09 & 1.08 \\
\hline \multirow[t]{4}{*}{ Case mix } & Resident restraint prevalence & 0.059 & 0.27 & 1.06 \\
\hline & Resident incontinence prevalence & -0.124 & 0.09 & 0.88 \\
\hline & Resident psychoactive drug prevalence & -0.023 & 0.40 & 0.98 \\
\hline & Resident bedfast prevalence & 0.048 & 0.50 & 1.05 \\
\hline \multirow[t]{2}{*}{ Payer mix } & Residents with Medicaid payment (v. Private pay) & 0.161 & 0.03 & 1.18 \\
\hline & Residents with Medicare payment (v. Private pay) & -0.158 & 0.10 & 0.85 \\
\hline \multirow[t]{2}{*}{ Ownership } & Ownership: not for profit (v. For profit) & -0.723 & 0.00 & 0.49 \\
\hline & Ownership: government (v. For profit) & -0.965 & 0.00 & 0.38 \\
\hline \multirow[t]{5}{*}{ Affiliation } & Hospital affiliation & 0.051 & 0.30 & 1.05 \\
\hline & Chain affiliation: small chain (v. independent) & 1.113 & 0.00 & 3.04 \\
\hline & Chain affiliation: mid-sized chain (v. independent) & 1.185 & 0.00 & 3.27 \\
\hline & Chain affiliation: large chain (v. independent) & 1.556 & 0.00 & 4.74 \\
\hline & Chain-owned home was acquired within past 2 periods & -0.432 & 0.00 & 0.65 \\
\hline \multirow[t]{2}{*}{ Size and utilization } & Total beds $(\times 100)$ & -0.049 & 0.05 & 0.95 \\
\hline & Capacity utilization & -0.464 & 0.00 & 0.63 \\
\hline \multicolumn{5}{|l|}{ Chain characteristics } \\
\hline & Chain ownership: for-profit & -0.034 & 0.32 & 0.97 \\
\hline & Chain size: no. of homes & -0.448 & 0.00 & 0.64 \\
\hline & Chain deficiencies mean & 0.149 & 0.00 & 1.16 \\
\hline & Chain ulcer prevalence mean & 3.629 & 0.00 & 37.66 \\
\hline & Chain staff per resident mean & 0.208 & 0.00 & 1.23 \\
\hline \multicolumn{5}{|c|}{ Local market competition } \\
\hline & Beds per capita & -21.851 & 0.18 & 0.00 \\
\hline & Market concentration: HHI & -0.225 & 0.00 & 0.80 \\
\hline & No. of nursing homes in county $(\times 100)$ & -0.118 & 0.00 & 0.89 \\
\hline & Hospital-affiliated competition $(\times 100)$ & 0.606 & 0.12 & 1.83 \\
\hline \multicolumn{5}{|c|}{ State and regional characteristics } \\
\hline \multirow[t]{3}{*}{ Reimbursement } & Medicaid expenditure/medicaid population $(\times 100)$ & -0.006 & 0.12 & 0.99 \\
\hline & Medicare expenditure/medicare population $(\times 100)$ & 0.260 & 0.00 & 1.30 \\
\hline & Medicaid reimbursement rate $(\times 100)$ & -0.870 & 0.00 & 0.42 \\
\hline Regulation & State regulation: certificate of need & -0.137 & 0.00 & 0.87 \\
\hline & State regulation: construction moratorium & -0.027 & 0.35 & 0.97 \\
\hline Region & Region: northeast (v. Far west) & -0.348 & 0.00 & 0.71 \\
\hline & Region: Mid-Atlantic (v. Far west) & -0.567 & $<.0001$ & 0.57 \\
\hline & Region: Great Lakes (v. Far west) & -0.499 & $<.0001$ & 0.61 \\
\hline & Region: Prairie states (v. Far west) & -0.751 & $<.0001$ & 0.47 \\
\hline & Region: Southeast (v. Far west) & -0.490 & $<.0001$ & 0.61 \\
\hline & Region: Southwest (v. Far west) & -0.477 & $<.0001$ & 0.62 \\
\hline & Region: Rockies (v. Far west) & -0.307 & 0.00 & 0.74 \\
\hline Time & & & & \\
\hline & Days between inspections & 0.211 & 0.00 & 1.23 \\
\hline & Calendar year: 1993 (v. 1992) & -0.518 & 0.00 & 0.60 \\
\hline & Calendar year: 1994 (v. 1992) & -0.633 & 0.00 & 0.53 \\
\hline & Calendar year: 1995 (v. 1992) & -0.597 & 0.00 & 0.55 \\
\hline & Calendar year: 1996 (v. 1992) & -0.556 & 0.00 & 0.57 \\
\hline & Calendar year: 1997 (v. 1992) & -1.029 & 0.00 & 0.36 \\
\hline & Intercept & -2.556 & 0.00 & 0.08 \\
\hline & $-2 \times$ No-covariate loglikelihood & 38931.2 & & \\
\hline & Model LL ratio $(\mathrm{df}=50)$ & 4824.6 & & \\
\hline & Cases (acquisitions) & 83504 & (5198) & \\
\hline
\end{tabular}

${ }^{\mathrm{a}}$ Note: Where indicated, we multiplied coefficients by 100 . 
The key result in Table 2 is that nursing home chains tend to acquire lower quality homes, regardless of whether a chain's motives are to improve the target's performance (i.e., reduce deficiencies and pressure ulcers), or to seize an opportunity to enter into a local market by acquiring a poor performing home at a 'bargain' price.

\section{Acquisition Consequences}

Table 3 presents the analysis of the effects of acquisition on changes in facilities' health quality. We focus the discussion on the tests of $\mathrm{H} 2-\mathrm{H} 4$. As in Table 2, the reduction in the number of cases stems from the fact that the dependent variables record one-period changes.
The dependent variable in model 1 of Table 3 is a one-period change in the number of health deficiencies that the target facility receives on its annual inspection; in model 2 , the dependent variable is a one-period change in the proportion of residents with pressure ulcers. In these models, positive parameter estimates indicate an increase in the prevalence of deficiency citations (model 1) or in pressure ulcers (model 2) and, hence, declining health quality.

Before turning to the hypotheses, it is important to recognize that both acquired and non-acquired units will have a 'regression to the mean' tendency, such that high-performing facilities will tend to reduce performance from year to year and low performing facilities will tend to improve. We control for regression to the mean on health performance by including the main effects of the

\section{Table 3. OLS estimates of impact of chain acquisition on changes in health quality at target (neg. coefficient =improved health quality, i.e., fewer ulcers or fewer deficiencies; positive coefficient $=$ declining health quality)}

\begin{tabular}{|c|c|c|c|c|}
\hline \multirow[b]{2}{*}{ Variable (Vector in equation (1)) } & \multicolumn{2}{|c|}{ 1. Change in deficiencies } & \multicolumn{2}{|c|}{ 2. Change in ulcers } \\
\hline & $\overline{\text { Coef. }}$ & $p>t$ & Coef. & $p>t$ \\
\hline \multicolumn{5}{|l|}{$\begin{array}{l}\text { Acquisition consequences, independent of } \\
\text { target and acquirer performance }(A)\end{array}$} \\
\hline $\mathrm{H} 2+$ Acquisition, period 1 & 0.083 & 0.00 & 0.008 & 0.00 \\
\hline Acquisition, period 2 & 0.0000 & 0.50 & 0.004 & 0.04 \\
\hline Acquisition, period 3 & -0.027 & 0.27 & 0.001 & 0.40 \\
\hline Acquisition, period 4 & -0.012 & 0.39 & -0.003 & 0.20 \\
\hline \multicolumn{5}{|l|}{ Target performance $\left(A \times X^{\prime}\right)^{\mathrm{a}}$} \\
\hline H3-Acquisition period $1 \times$ target problems & -0.042 & 0.00 & -0.055 & 0.00 \\
\hline $\mathrm{H} 3$-Acquisition period $2 \times$ target problems & -0.010 & 0.29 & -0.070 & 0.00 \\
\hline H3-Acquisition period $3 \times$ target problems & -0.016 & 0.24 & -0.031 & 0.11 \\
\hline H3-Acquisition period $4 \times$ target problems & -0.022 & 0.19 & -0.008 & 0.37 \\
\hline \multicolumn{5}{|l|}{ Acquirer performance $\left(A \times Z^{\prime}\right)^{\mathrm{a}}$} \\
\hline $\mathrm{H} 4+$ Acquisition period $1 \times$ acquirer problems & 0.071 & 0.00 & -0.055 & 0.00 \\
\hline $\mathrm{H} 4+$ Acquisition period $2 \times$ acquirer problems & 0.057 & 0.02 & 0.016 & 0.29 \\
\hline $\mathrm{H} 4+$ Acquisition period $3 \times$ acquirer problems & 0.076 & 0.02 & 0.019 & 0.33 \\
\hline $\mathrm{H} 4+$ Acquisition period $4 \times$ acquirer problems & 0.044 & 0.16 & 0.079 & 0.04 \\
\hline \multicolumn{5}{|l|}{ Nursing home health outcomes $(Y)$} \\
\hline Health deficiencies & -0.785 & 0.00 & 0.002 & 0.00 \\
\hline Resident ulcer prevalence & 0.369 & 0.00 & -0.787 & 0.00 \\
\hline \multicolumn{5}{|l|}{ Facility size and utilization $(X)$} \\
\hline Total beds $(\times 1000)$ & 0.9191 & 0.00 & 0.016 & 0.00 \\
\hline Capacity utilization & -0.184 & 0.00 & -0.016 & 0.00 \\
\hline \multicolumn{5}{|l|}{ Facility affiliation and ownership $(X)$} \\
\hline Hospital affiliation & 0.052 & 0.00 & 0.010 & 0.00 \\
\hline Chain affiliation: small chain & 0.019 & 0.16 & -0.003 & 0.00 \\
\hline Chain affiliation: mid-sized chain & 0.004 & 0.43 & -0.001 & 0.14 \\
\hline Chain affiliation: large chain & 0.014 & 0.28 & -0.002 & 0.06 \\
\hline Ownership: not for profit & -0.107 & 0.00 & -0.006 & 0.00 \\
\hline Ownership: government & -0.082 & 0.00 & -0.006 & 0.00 \\
\hline
\end{tabular}


Table 3 (continued)

\begin{tabular}{|c|c|c|c|c|}
\hline \multirow[b]{2}{*}{ Variable (Vector in equation (1)) } & \multicolumn{2}{|c|}{ 1. Change in deficiencies } & \multicolumn{2}{|c|}{ 2. Change in ulcers } \\
\hline & Coef. & $p>t$ & Coef. & $p>t$ \\
\hline \multicolumn{5}{|l|}{ Nursing home operating strategy $(X)$} \\
\hline Staff per resident & -0.077 & 0.00 & 0.005 & 0.00 \\
\hline RNs per total care staff & -0.350 & 0.00 & 0.001 & 0.41 \\
\hline Rehabilitation beds per total beds & -0.090 & 0.04 & -0.008 & 0.00 \\
\hline Alzheimer's beds per total beds & -0.044 & 0.15 & -0.010 & 0.00 \\
\hline Resident specialty services use prevalence & -0.028 & 0.02 & 0.013 & 0.00 \\
\hline \multicolumn{5}{|l|}{ Resident case-mix and payer sources $(X)$} \\
\hline Resident restraint prevalence & 0.065 & 0.00 & 0.016 & 0.00 \\
\hline Resident incontinence prevalence & -0.026 & 0.12 & 0.005 & 0.00 \\
\hline Resident psychoactive drug prevalence & -0.015 & 0.24 & -0.019 & 0.00 \\
\hline Resident bedfast prevalence & 0.054 & 0.11 & 0.098 & 0.00 \\
\hline Residents with Medicaid payment & 0.303 & 0.00 & -0.001 & 0.23 \\
\hline Residents with Medicare payment & -0.050 & 0.04 & 0.039 & 0.00 \\
\hline \multicolumn{5}{|l|}{ Time period and other ownership change $(R)$} \\
\hline Calendar year: 1993 (v. 1992) & 0.017 & 0.08 & 0.002 & 0.00 \\
\hline Calendar year: 1994 (v. 1992) & -0.067 & 0.00 & 0.004 & 0.00 \\
\hline Calendar year: 1995 (v. 1992) & -0.232 & 0.00 & -0.002 & 0.00 \\
\hline Calendar year: 1996 (v. 1992) & -0.346 & 0.00 & -0.007 & 0.00 \\
\hline Calendar year: 1997 (v. 1992) & -0.375 & 0.00 & -0.003 & 0.00 \\
\hline Days between inspections $(\times 1000)$ & -0.361 & 0.00 & -0.012 & 0.00 \\
\hline Change in ownership (non-chain) & 0.067 & 0.00 & 0.003 & 0.01 \\
\hline \multicolumn{5}{|l|}{ Chain characteristics $(Z)$} \\
\hline Chain ownership: for-profit & -0.024 & 0.06 & 0.002 & 0.02 \\
\hline Chain size: no. of homes & -0.0002 & 0.00 & 0.000 & 0.44 \\
\hline Chain deficiencies mean & 0.052 & 0.00 & -0.000 & 0.40 \\
\hline Chain ulcer prevalence mean & 0.279 & 0.02 & 0.079 & 0.00 \\
\hline Chain staff per resident mean & -0.026 & 0.01 & -0.001 & 0.00 \\
\hline \multicolumn{5}{|l|}{ Market characteristics $(M)$} \\
\hline Beds per capita & -5.826 & 0.15 & -1.237 & 0.00 \\
\hline Market concentration: HHI & -0.012 & 0.28 & 0.001 & 0.22 \\
\hline No. of nursing homes in county $(\times 1000)$ & -0.131 & 0.03 & 0.036 & 0.00 \\
\hline Hospital-affiliated competition & 0.001 & 0.24 & 0.001 & 0.00 \\
\hline Urban-rural continuum (high = rural) & -0.011 & 0.00 & -0.001 & 0.00 \\
\hline \multicolumn{5}{|l|}{ State and regional characteristics $(M)$} \\
\hline Medicaid reimbursement rate $(\times 1000)$ & -0.063 & 0.42 & -0.047 & 0.00 \\
\hline Medicaid expenditure/Medicaid population $(\times 1000)$ & 0.015 & 0.12 & -0.006 & 0.00 \\
\hline Medicare expenditure/Medicare population $(\times 1000)$ & 0.110 & 0.10 & 0.001 & 0.44 \\
\hline State regulation: certificate of Need & -0.002 & 0.42 & 0.0002 & 0.36 \\
\hline State regulation: construction moratorium & -0.063 & 0.00 & -0.0001 & 0.46 \\
\hline Region: Far west (v. Southwest) & -0.031 & 0.13 & 0.002 & 0.11 \\
\hline Region: Great Lakes (v. Southwest) & -0.049 & 0.03 & 0.012 & 0.00 \\
\hline Region: Mid-Atlantic (v. Southwest) & -0.015 & 0.20 & 0.003 & 0.00 \\
\hline Region: Northeast (v. Southwest) & 0.057 & 0.01 & -0.005 & 0.00 \\
\hline Region: Prairie states (v. Southwest) & -0.025 & 0.07 & 0.003 & 0.00 \\
\hline Region: Rockies (v. Southwest) & -0.046 & 0.02 & 0.002 & 0.11 \\
\hline Region: Southeast (v. Southwest) & -0.001 & 0.48 & -0.010 & 0.00 \\
\hline Intercept & 1.033 & 0.00 & 0.065 & 0.00 \\
\hline Cases & 83006 & & 83042 & \\
\hline$R^{2}$ & 0.42 & & 0.47 & \\
\hline
\end{tabular}

Note: Where indicated, we multiplied coefficients by $1000 .^{\text {a }}$ The performance measure is ulcer prevalence (target or acquirer) in column 1, health deficiencies (target or acquirer) in column 2 ; high values of the performance value indicates poor performance (i.e., many problems) of the target or acquirer. 
prior period performance of a facility (the $Y$ vector variables: Health deficiencies in model 1; Resident ulcer prevalence in model 2). As expected, the negative coefficients for lagged performance indicate that facilities with previously high ulcer rates and deficiency citations tend to improve, while those with low ulcer rates and deficiency levels tend to worsen.

The results in Table 3 support $\mathrm{H} 2$, which predicted short-term decline in performance following acquisitions. The significant positive parameter estimates for Acquisition, period 1 in both models 1 and 2, plus an additional significant effect of Acquisition, period 2 for pressure ulcers, indicate an initial main effect of acquisition in which quality often suffers. Thus, we find that residents' health quality may suffer when their home is acquired, if we do not take the characteristics of their home and their acquirer into account.

Table 3 supports $\mathrm{H} 3$, which predicted that quality would improve at poor-quality targets. We tested the hypothesis by interacting each period since acquisition with quality characteristics of the target facility (for this and the other interaction variables included in the analyses, the interaction variables take a value of 0 for nursing homes with no relevant acquisition). The coefficients for the Acquisition $\times$ Target problems interaction terms are negative in all four periods in both columns, with significance in periods 1 and 2 for ulcers and period 1 for deficiencies.

Table 3 supports H4, which predicted that the quality of the acquiring chains affects performance in acquired facilities. We tested the hypothesis by interacting each period since acquisition with lagged quality characteristics of the acquiring chain. Acquisition by low-quality chains (i.e., acquirers with more problems) often leads to declining health quality at the target facilities. Seven of the eight coefficients for the Acquisition $\times$ Acquirer problems interaction terms are positive. The effects are significant in the first three periods for health deficiencies (model 1). For pressure ulcers, though, significant quality influences take longer to emerge (model 2). Indeed, the significant negative coefficient for the period 1 interaction in model 2, which indicates that ulcers initially decline for homes acquired by a chain with higher rates of pressure ulcers among residents, is unexpected; we do not have an obvious explanation for this result. By period 2, however, the expected relationship between poor-acquirer quality and increased ulcer prevalence emerges, with the result being statistically significant in period 4 .

Thus, the main effects on health quality of being acquired must be considered alongside the interactions between acquisition and the quality of both the acquiring chain and target facility. Combined, the main effects and interaction effects of acquisition indicate that post-acquisition target performance depends on the prior performance of both the target and the chain.

The interaction term estimates of acquisition with target and acquirer quality indicate substantive changes in health performance. For example, the deficiencies for a facility with a state-weighted average of 2.21 health deficiencies (1 standard deviation above the facility mean of 1.07 ) would produce a reduction of 0.20 deficiencies by the fourth period after acquisition (about a $9 \%$ reduction). In parallel, a facility that is acquired by a purchaser with 1.91 deficiencies (1 standard deviation above the chain deficiencies mean of 1.07) would add 0.47 deficiencies by the fourth post-acquisition period (i.e., about $45 \%$ of the facility mean deficiencies level). Similarly, pressure ulcers at a target facility with a mean incidence of 0.15 ( 1 standard deviation above the mean of 0.07 ) would produce an ulcers reduction of 0.02 by the fourth period (about a 16\% reduction). Moreover, a facility that is acquired by a purchaser with an ulcer rate of 0.07 ( 1 standard deviation about the chain pressure ulcers rate of 0.03 ) would incur an increased rate of about 0.005 (about $6 \%$ of the facilities pressure ulcer mean). These acquisition effects translate into a better quality of life for some residents at poor-quality targets and a poorer quality of life for residents of homes acquired by poor-quality chains.

Overall, the estimates in Table 3 indicate that the effects of acquisition on facility health performance are contingent on the quality characteristics of the target (H3) and acquirer (H4). Acquisition by a high-quality chain or of a lowquality target often mitigates the initially disruptive effects of being acquired and improves quality for several periods. At the same time, acquisition by a low-quality chain or of a high-quality target can exacerbate problems.

Figure 1 illustrates the cumulative multiperiod effects on post-acquisition changes in a target's pressure health deficiencies and ulcer incidence following acquisition as a joint function of the 
Change in target health deficiencies (HD)
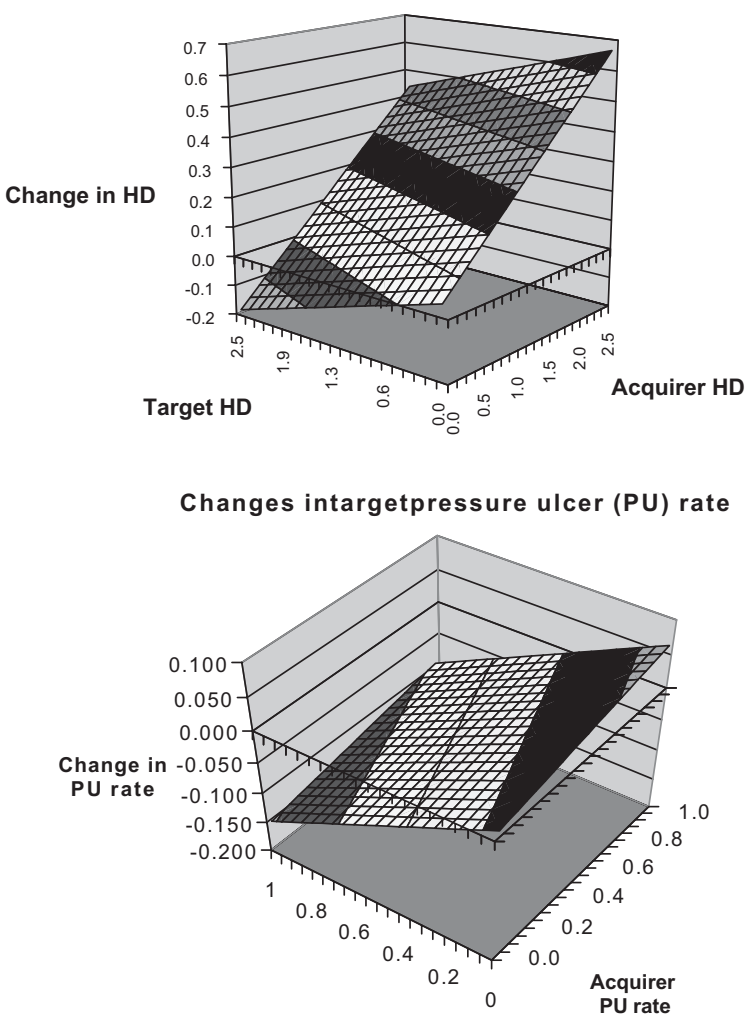

Target PU rate

Figure 1. Cumulative four-period effect of target and chain health performance on changes in target health performance (increase $=$ declining resident health quality).

target's and its acquirer's performance (using the parameter estimates in columns 1 and 2 of Table 3). ${ }^{5}$ As both panels of the figure show, target quality problems tend to increase most when the targets have few health quality problems and when acquiring chains have substantial quality problems (the upper right corner of each surface in the figure). Conversely, target problems decline when acquirers have few quality problems and targets have many quality problems (the lower left corners of the surfaces in the figure). For both cases, little change occurs when both acquirer and target already have good quality (the front corner of both panels). At the same time, lesser but striking changes in performance occur when both target and acquirer have many quality problems (the rear corner of the panels). For health deficiencies, in the upper panel, quality declines moderately when both acquirer and target have poor quality. For pressure ulcers, though, quality actually improves when both acquirer and target are poor, but at a lower rate than if the acquirer has good quality, suggesting that even poor acquirers may be able to solve some of the problems at particularly poor targets. The key implication of the patterns in Figure 1 is that postacquisition changes in target performance depend on target and acquirer quality together. The patterns speak both to the striking problems that can occur, particularly when poor quality chains purchase good quality homes, and to the benefits than can arise when good quality chains purchase poor quality homes.

We emphasize the dynamic dimension of this approach to studying performance changes. An acquisition done one year has short-term and longterm effects based on the partial adjustment analytic model. The model initially examines changes in health performance during the period following acquisitions, after which those changes become part of the lagged dependent variable. Figure 2 depicts the trends in health deficiency changes over the four periods of the study. The figure shows an initial period 1 increase in health deficiencies, at almost all combinations of target and acquirer quality. Over time, though, the potential for reduced health deficiencies progressively becomes stronger, as the initial disruptive main effect of acquisitions dampens. Moreover, the figure also shows that increased deficiencies tend to reach particularly high levels during the first period, while subsequent periods incur lower maximum increases.

The effects of chain characteristic control variables provide further evidence for the conclusion that the quality of health performance in a chain influences performance at member facilities. The prevalence of pressure ulcers increases in homes belonging to chains in which all the other facilities also have high pressure ulcer prevalence (Chain ulcer prevalence mean in model 2). Similarly, deficiency citations tend to increase at homes belonging to chains in which the other facilities also have on average high citation rates (Chain deficiencies mean in model 1). These effects are not conditional on recent acquisition but, instead, demonstrate that among all chain members (both newly acquired and long-standing members), the characteristics of the chain affect local service quality. 


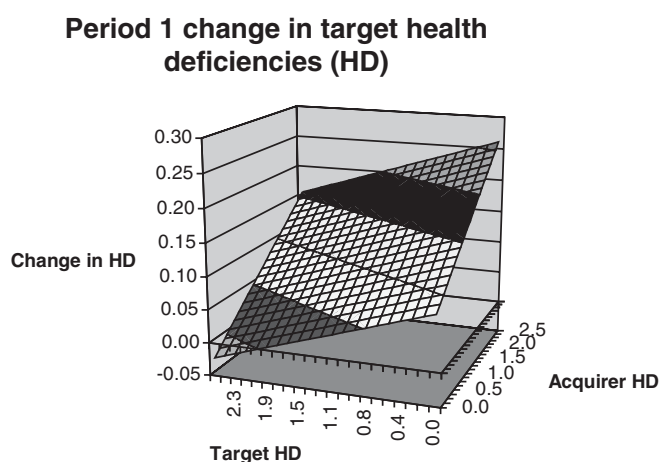

Period 3 change in target health deficiencies (HD)

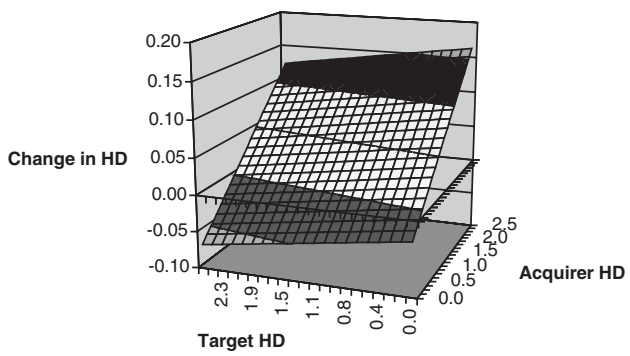

Period 2 change in target health deficiencies (HD)

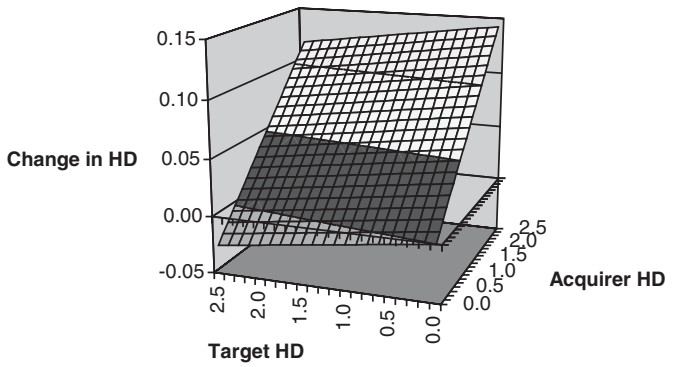

Period 4 change in target health deficiencies (HD)

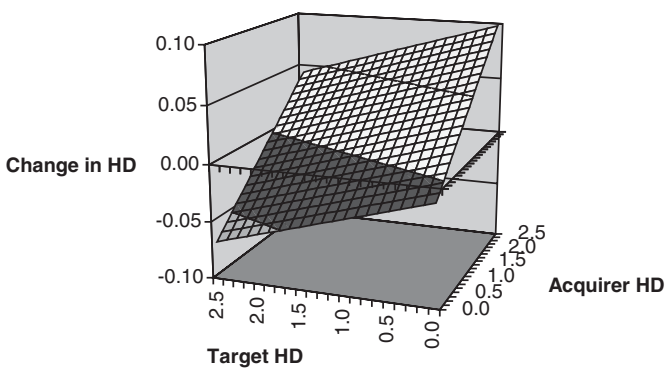

Figure 2. Per-period trends in effect of target and chain health performance on changes in target health performance (health deficiencies). (increase $=$ declining resident health quality).

The results also demonstrate that chain size and facility size have different effects on health performance. Chains operating more homes (Chain size) tend to enjoy greater improvements in health deficiencies. In contrast, larger facilities (Total beds) have ongoing decreases in health quality, with greater increases in both pressure ulcer rates and deficiency citations. These effects of size may reflect larger chains' potential for experiential learning (Ingram and Baum, 1997), on the one hand, and the difficulty of maintaining quality in large facilities with broader case-mix or more complicated residential needs, on the other.

Placing the results in perspective, the findings suggest that health performance of nursing homes are characterized by relatively low inertia for units, yet by a high influence of the performance of the acquirer. The overall effect of lagged target health problems on health performance changes is around -0.79 for both deficiencies and ulcers (Table 3). Although acquisitions play a striking role, it is small relative to the very low inertia in the process. Thus, health performance of all nursing homes adjust quickly to changes in the predictor variables, while exogenous shocks such as acquisitions have short memory. The coefficients associated with $\mathrm{H} 3$ and $\mathrm{H} 4$ suggest that many adjustments based on target and acquirer performance happen soon after acquisition. This combination of low unit inertia with high adaptation to corporate performance is intriguing and likely reflects the nature of multiunit service organizations in which many competences arise in administrative procedures and organizational routines, rather than in physical assets and technical advantages. Nursing homes, for example, can reduce the incidence of pressure ulcers and health deficiencies through instituting clinical protocols and introducing better administrative quality controls. Thus, the transfer of capabilities that are not capital-intensive may particularly suit standardization in many service industries.

\section{DISCUSSION AND CONCLUSION}

Although several studies of nursing homes have included chain ownership as an important 
variable, this study is unique in its dynamic focus on the acquisition process - both pre and post- -"' and its rich information on the characteristics of chains. As such, it provides quantitative insight into a phenomenon, the consolidation of nursing homes under chain ownership, of great human and social significance to a fast-aging nation.

The results have both industry-specific and more general implications. The industry-specific findings challenge the view that nursing homes acquisitions are 'bad' per se, and demonstrate that chain acquisitions can offer benefits for resident welfare, while at the same time highlighting the conditions under which acquisitions lead to problems. Health performance will suffer if the acquiring chain has a history of problems or if the target home has previously achieved a high-quality level. But acquisitions by high-quality chains or of poorquality homes can result in substantial quality improvements. Because residents of poor-quality homes are most likely to benefit from acquisition, the fact that the first part of our analysis finds that chains tend to purchase facilities with poor preacquisition quality is a reassuring result.

The findings suggest that good health performance may be compatible with chain management. The major benefits of acquisitions, and of chain ownership, are likely to derive from the discipline and experience of corporate managers and the availability to the target homes of new operating routines. Thus, it is important to continue studying how the transfer of capabilities occurs and what specific changes contribute to improved resident health.

Our findings have significant policy implications. We find no evidence that the long-term quality of resident care need suffer as a consequence of a chain acquiring a nursing home. This should temper concerns about the growth of nursing home chains. At the same time, though, better policy regarding monitoring of acquisitions, particularly by poor-performing chains, might help to avoid the systematic, negative consequences.

Notably, our findings and policy conclusions regarding the impact of chaining on resident welfare differ from those of Harrington et al. (2001) in their study of care quality in US nursing home chains. We believe, however, that our longitudinal findings are consistent with their cross-sectional findings, also based on the OSCAR data, that non-chain nursing homes provided higher quality care in 1997 than nursing homes operated by chains. Because, as our analysis shows, nursing homes chains tend to acquire poor-performing facilities, a cross-sectional comparison of chain and non-chain facilities may show non-chain facilities outperforming chain facilities. This finding results from the equilibrium assumption implicit in such a cross-sectional analysis, which does not account for the dynamic effects of chain acquisition. Relatively poorer chain quality may thus be observed in cross-section as a result of chains' recently acquiring poor performing targets. These different conclusions underscore the need to understand better the dynamic impact of chaining in the nursing home industry.

At a more general level, the study offers insights concerning strategic factors that promote acquisition and drive expansion of service sector chains. Chain expansion frequently proceeds primarily through new building (e.g., Blockbuster, McDonald's) or acquisition and conversion of existing operations (e.g., Century 21, Best Western). While growth through acquisition can occur more quickly than new building, achieving rapid expansion requires readily available acquisition targets. Consequently, in sectors where multiunit service chains expand primarily through acquisition, as do nursing home chains, it seems likely that the tendency to acquire poor-quality operations that offer opportunities for improvement will be common. Our predictions specifying the relationships between post-acquisition performance and the performance of the target and acquirer also are also likely to generalize to such settings.

That said, our focus has been on a context, common to the multiunit chain form across a range of economic sectors, in which many capabilities are routine intensive, where transfer involves few physical assets and allows recipient components to adjust quickly to the inherent routines of the chain. Attempts to transfer more asset-dependent capabilities to components may require more time and potentially be subject to more errors in-transfer. The distinction between routine-intensive and asset-dependent transfer may influence the ease and effectiveness of transfer, and so may influence the rate and cost at which a chain achieves standardization. Future research should consider this possibility.

Our study is premised on the idea that acquisitions provide chains with an opportunity to transfer, replicate and profit further from effective 
capabilities and skills they have developed (Baum et al., 2000; Mitchell et al., 2002). In turn, as a result, the transfer of new capabilities might lead to better care at acquired homes. This study bypasses, however, the processes by which chains transfer capabilities to their newly acquired units. It is possible, for example, that as chains act to transfer capabilities and standardize their new acquisitions, they force some of these units to abandon successful practices while adopting inferior ones and hence, result in lower performance in the affected units (Greve, 1999; Ingram and Baum, 1997). The systematic relationships between acquisitions and health performance we found here point to the need for further detailed research on the process, nature, and content of capability transfer itself (Mitchell et al., 2002).

The study has several limits. First, the accounting of local competition in our models is incomplete because we were unable to obtain data about alternative facilities and services (e.g., assisted living facilities, home-based care, adult day-care centers) that serve the same market as nursing homes. A second limitation concerns accounting for other factors that influence acquisition. For example, closure of a nursing home by the state might lead the facility to be sold to another operator. A chain may acquire the poorly performing home, which presents itself as a bargain under these specific circumstances, despite generally pursuing an acquisition strategy that prescribes acquisition of high-performing nursing homes.
We believe the study provides robust conclusions concerning key causes and consequences of nursing home chaining. Chain formation in the long-term care industry has raised strong concerns about the potential negative impact on the quality of resident health care. This study shows that chain acquisition is not a problem per se. Instead, how health quality changes depends on who bought whom rather than just on the 'bought by chain' blanket label.

\section{Acknowledgements}

We greatly appreciate thoughtful suggestions from an $M D E$ reviewer. The Blue Cross - Blue Shield Foundation of Michigan has supported work related to this study.

\section{APPENDIX A}

Table A1 provides descriptive statistics and Table A2 defines each of the control variables and lists the states in each region.

\section{NOTES}

1. Table 1 reports a smaller number of homes in 1991, suggesting that the first year of the data omits some cases. We replicated the analyses for the 1992-1997 period, finding no material differences. We also found that a few facilities disappeared from the data, with about 130 homes per year disappearing from the sample from 1991 through 1995 (when about 1\%-2\%

\section{Table A1. Descriptive Statistics}

\begin{tabular}{|c|c|c|c|c|}
\hline Variable & Mean & s.d. & Min. & Max. \\
\hline Chain-owned home was acquired within past two periods & 0.07 & 0.25 & 0.00 & 1.00 \\
\hline Change in health deficiencies & -0.08 & 1.31 & -18.62 & 19.23 \\
\hline Change in pressure ulcer prevalence & -0.00 & 0.08 & -1.00 & 1.00 \\
\hline Acquisition, period 1 & 0.06 & 0.24 & 0.00 & 1.00 \\
\hline Acquisition, period 2 & 0.04 & 0.20 & 0.00 & 1.00 \\
\hline Acquisition, period 3 & 0.03 & 0.16 & 0.00 & 1.00 \\
\hline Acquisition, period 4 & 0.03 & 0.17 & 0.00 & 1.00 \\
\hline Acquisition period $1 \times$ target deficiencies & 0.08 & 0.44 & 0.00 & 16.08 \\
\hline Acquisition period $2 \times$ target deficiencies & 0.05 & 0.33 & 0.00 & 17.61 \\
\hline Acquisition period $3 \times$ target deficiencies & 0.03 & 0.24 & 0.00 & 12.66 \\
\hline Acquisition period $4 \times$ target deficiencies & 0.03 & 0.24 & 0.00 & 15.13 \\
\hline Acquisition period $1 \times$ acquirer deficiencies & 0.06 & 0.29 & 0.00 & 5.82 \\
\hline Acquisition period $2 \times$ acquirer deficiencies & 0.05 & 0.26 & 0.00 & 9.32 \\
\hline Acquisition period $3 \times$ acquirer deficiencies & 0.03 & 0.20 & 0.00 & 6.72 \\
\hline Acquisition period $4 \times$ acquirer deficiencies & 0.03 & 0.18 & 0.00 & 8.70 \\
\hline Acquisition period $1 \times$ target ulcer prevalence & 0.01 & 0.03 & 0.00 & 1.00 \\
\hline Acquisition period $2 \times$ target ulcer prevalence & 0.00 & 0.02 & 0.00 & 1.00 \\
\hline Acquisition period $3 \times$ target ulcer prevalence & 0.00 & 0.02 & 0.00 & 0.63 \\
\hline
\end{tabular}




\begin{tabular}{|c|c|c|c|c|}
\hline $\begin{array}{l}\text { Table A1 (continued) } \\
\text { Variable }\end{array}$ & Mean & s.d. & Min. & Max. \\
\hline Acquisition period $4 \times$ target ulcer prevalence & 0.00 & 0.02 & 0.00 & 0.57 \\
\hline Acquisition period $1 \times$ acquirer ulcer prevalence & 0.00 & 0.02 & 0.00 & 0.42 \\
\hline Acquisition period $2 \times$ acquirer ulcer prevalence & 0.00 & 0.02 & 0.00 & 0.64 \\
\hline Acquisition period $3 \times$ acquirer ulcer prevalence & 0.00 & 0.01 & 0.00 & 0.56 \\
\hline Acquisition period $4 \times$ acquirer ulcer prevalence & 0.00 & 0.01 & 0.00 & 0.36 \\
\hline Health deficiencies & 1.07 & 1.14 & 0.00 & 20.04 \\
\hline Resident ulcer prevalence & 0.07 & 0.08 & 0.00 & 1.00 \\
\hline Total beds & 106.48 & 66.77 & 4.00 & 500.00 \\
\hline Capacity utilization & 0.85 & 0.20 & 0.00 & 1.00 \\
\hline Hospital affiliation & 0.09 & 0.28 & 0.00 & 1.00 \\
\hline Chain affiliation: small chain & 0.14 & 0.35 & 0.00 & 1.00 \\
\hline Chain affiliation: mid-sized chain & 0.10 & 0.30 & 0.00 & 1.00 \\
\hline Chain affiliation: large chain & 0.13 & 0.34 & 0.00 & 1.00 \\
\hline Ownership: not for profit & 0.26 & 0.44 & 0.00 & 1.00 \\
\hline Ownership: government & 0.07 & 0.25 & 0.00 & 1.00 \\
\hline Ownership: for profit & 0.67 & 0.50 & 0.00 & 1.00 \\
\hline Staff per resident & 0.80 & 0.32 & 0.00 & 3.00 \\
\hline RNs per total care staff & 0.13 & 0.11 & 0.00 & 1.00 \\
\hline Rehabilitation beds per total beds & 0.01 & 0.06 & 0.00 & 1.00 \\
\hline Alzheimer's beds per total beds & 0.02 & 0.08 & 0.00 & 1.00 \\
\hline Resident restraint prevalence & 0.20 & 0.16 & 0.00 & 1.00 \\
\hline Resident incontinence prevalence & 0.48 & 0.18 & 0.00 & 1.00 \\
\hline Resident psychoactive drug prevalence & 0.34 & 0.18 & 0.00 & 1.00 \\
\hline Resident specialty services use prevalence & 0.42 & 0.38 & 0.00 & 3.00 \\
\hline Resident bedfast prevalence & 0.06 & 0.09 & 0.00 & 1.00 \\
\hline Payer: residents with Medicaid payment & 0.63 & 0.27 & 0.00 & 1.00 \\
\hline Payer: residents with Medicare payment & 0.11 & 0.22 & 0.00 & 1.00 \\
\hline Payer: residents with private payment & 0.26 & 0.22 & 0.00 & 1.00 \\
\hline Calendar year: 1991 & 0.13 & 0.34 & 0.00 & 1.00 \\
\hline Calendar year: 1992 & 0.15 & 0.15 & 0.00 & 1.00 \\
\hline Calendar year: 1993 & 0.15 & 0.36 & 0.00 & 1.00 \\
\hline Calendar year: 1994 & 0.15 & 0.36 & 0.00 & 1.00 \\
\hline Calendar year: 1995 & 0.14 & 0.35 & 0.00 & 1.00 \\
\hline Calendar year: 1996 & 0.17 & 0.38 & 0.00 & 1.00 \\
\hline Calendar year: 1997 & 0.10 & 0.30 & 0.00 & 1.00 \\
\hline Days between inspections & 373.71 & 78.41 & 1.00 & 1549.00 \\
\hline Change in ownership (non-chain) & 0.03 & 0.17 & 0.00 & 1.00 \\
\hline Chain ownership: for-profit & 0.33 & 0.46 & 0.00 & 1.00 \\
\hline Chain size: no. of homes & 43.29 & 143.08 & 0.00 & 823.00 \\
\hline Chain deficiencies mean & 1.07 & 0.84 & 0.00 & 16.93 \\
\hline Chain ulcer prevalence mean & 0.03 & 0.04 & 0.00 & 0.89 \\
\hline Chain staff per resident mean & 0.41 & 0.63 & 0.00 & 3.00 \\
\hline Beds per capita & 0.00 & 0.00 & 0.00 & 0.03 \\
\hline Market concentration: $\mathrm{HHI}$ & 0.22 & 0.21 & 0.00 & 1.00 \\
\hline No. of nursing homes in county & 31.83 & 56.61 & 1.00 & 408.00 \\
\hline Hospital-affiliated competition & 0.40 & 2.89 & 0.00 & 59.00 \\
\hline Urban-rural continuum $($ high $=$ rural $)$ & 3.02 & 2.83 & 0.00 & 9.00 \\
\hline Medicaid reimbursement rate & 79.07 & 20.51 & 50.32 & 155.50 \\
\hline Medicaid expenditure/Medicaid population & 1101.00 & 572.29 & 19.61 & 3235.00 \\
\hline Medicare expenditure/Medicare population & 117.64 & 80.21 & 5.38 & 434.78 \\
\hline State regulation: certificate of Need & 0.57 & 0.49 & 0.00 & 1.00 \\
\hline State regulation: construction moratorium & 0.13 & 0.34 & 0.00 & 1.00 \\
\hline Region: Far west & 0.07 & 0.25 & 0.00 & 1.00 \\
\hline Region: Great Lakes & 0.11 & 0.32 & 0.00 & 1.00 \\
\hline Region: Mid-Atlantic & 0.20 & 0.40 & 0.00 & 1.00 \\
\hline Region: Northeast & 0.14 & 0.35 & 0.00 & 1.00 \\
\hline Region: Prairie states & 0.22 & 0.41 & 0.00 & 1.00 \\
\hline Region: Rockies & 0.12 & 0.32 & 0.00 & 1.00 \\
\hline Region: Southeast & 0.03 & 0.18 & 0.00 & 1.00 \\
\hline Region: Southwest & 0.11 & 0.31 & 0.00 & 1.00 \\
\hline
\end{tabular}


Table A2. Variable Definitions

Variable (Vector in equation (1))

Definition

Acquisition occurrence (A)

Acquisition, period 1

Acquisition, period 2

Acquisition, period 3

Acquisition, period 4

Nursing home health outcomes $\left(Y, Y_{t}-Y_{t-1}\right)$ Health deficiencies

Resident ulcer prevalence

Change in health deficiencies

Change in pressure ulcer prevalence

Facility size and utilization $(X)$

Total beds

Capacity utilization

Facility affiliation and ownership $(X)$

Hospital affiliation

Chain affiliation: small chain

Chain affiliation: mid-sized chain

Chain affiliation: large chain

Ownership: not for profit

Ownership: government

Ownership: for profit

Chain-owned home was acquired within

past two periods

Nursing home operating strategy $(X)$

Staff per resident

RNs per total care staff

Change in staff intensity

Specialty beds per total beds

Change in specialty bed intensity

Rehabilitation beds per total beds Change in rehabilation bed intensity

Alzheimer's beds per total beds

Change in Alzherimer's bed intensity

Resident specialty services use prevalence

Resident case-mix and payer sources $(X)$

Resident restraint prevalence

Resident incontinence prevalence

Resident psychoactive drug prevalence

Resident bedfast prevalence

Payer: Residents with Medicaid payment

Payer: Residents with Medicare payment

Payer: Residents with private payment

Time period and other ownership change $(R)$

Calendar year dummy variables

Facility ownership changed since prior inspection; new owner is chain with two or more facilities

Facility ownership changed two periods ago

Facility ownership changed three periods ago

Facility ownership changed four or more periods ago. Note: If a facility was acquired for a second time during the study period, we restarted the count of years since acquisition

No. of health deficiencies reported in state inspection, divided by the mean deficiencies reported at facilities in that state; we also defined a squared term of this variable

Proportion of residents in facility reported to have pressure ulcers; we also defined a squared term of this variable

One period increase in deficiencies (number at current inspection minus number reported at prior inspection)

One period increase in pressure ulcer prevalence

Number of beds in facility

Residents per total beds

Facility reports affiliation with a hospital

Facility is member of chain with two to 10 facilities in inspection year Facility is member of chain with 11 to 50 facilities in inspection year

Facility is member of chain with more than 50 facilities in inspection year

Facility has non-profit ownership

Facility has government ownership

Facility has for-profit ownership

Home was acquired by its current chain owner within past two periods

FTE staff hours (RN, LPN, support, and specialty services staff) relative to the no. of residents in facility

Registered Nurses as a proporation of total care staff (RNs, LPNs, and aides) One period increase in staff per resident

No. of beds for specialty care needs (AIDS, Alzheimers, dialysis, children's disabilities, head trauma, hospice, Huntington's disease, specialty rehabilitation, and ventilator beds), as proportion of total beds in facility

One period increase in specialty bed intensity

No. of beds for rehabilitation care needs, as proportion of total beds in facility One period increase in rehabilitation beds per total beds

No. of beds for Alzheimer's disease care needs, as proportion of total beds in facility

One period increase in Alzheimer's beds per total beds

Proportion of residents receiving specialty-care services, summed across three types of services: Injections; physical and occupational therapy; and other (ostomy, respiratory, suction, IV therapy, tracheotomy)

Proportion of residents with restraints

Proportion of residents with bladder incontinence Proportion of residents receiving anti-psychotic drugs Proportion of residents who must remain in bed Proportion of residents receiving Medicaid payment Proportion of residents receiving Medicare payment Proportion of residents paying from private sources

Calendar year of inspection, dummy variables for each year from 1991 to 1997 
Table A2 (continued)

Variable (Vector in equation (1))

Days between inspections

Change in ownership (non-chain)

Chain health outcomes and operating strategy

Chain mean rehabilitation beds per total beds

Chain mean Alzheimer's beds per total beds

Chain specialty bed mean

Chain characteristics $(Z)$

Chain ownership: for-profit

Chain size: no. of homes

Chain mean beds

Chain deficiencies mean

Chain ulcer prevalence mean

Chain staff per resident mean

Market characteristics $(M)$

Beds per capita

Market concentration: HHI

No. of nursing homes in county

Hospital-affiliated competition

Urban-rural continuum (high $=$ rural)

State and regional characteristics $(M)$

Medicaid reimbursement rate

Medicaid expenditure/Medicaid population

Medicare expenditure/Medicare population

State population over 65

State regulation: certificate of Need

State regulation: construction moratorium

Region: far west

Region: Great Lakes

Region: Mid-Atlantic

Region: Northeast

Region: Prairie states

Region: Rockies

Region: Southeast

Region: Southwest
Definition

Number of days since last inspection

Nursing home was acquired by single-home holding company during the last four periods

Mean rehabilitation bed intensity of facilities in chain during year

Mean Alzheimer's bed intensity of facilities in chain during year

Mean specialty bed intensity of facilities in chain during year

Proportion of homes in a chain with for-profit ownership status Number of facilities in chain during calendar year of inspection Mean number of beds of a chain's facilities during year

Mean number of deficiencies reported across member facilities in chain during year

Mean pressure ulcer prevalence across member facilities in chain during year Mean staff intensity across member facilities of chain during year

No. of nursing home beds per person in county (based on 1990 county population)

Hirschman-Herfindahl index of concentration of nursing home facilities in county in a given year

Total number of facilities in county in a given year

No. of hospital-affiliated homes in county

Degree of urban-rural status of a county

State Medicaid daily reimbursement rate for nursing home care (mean of 1993 and 1998 rates, $r=0.86$ )

Total state Medicaid expenditures per state Medicaid population, for a given year

Total state Medicare expenditures per state Medicare population, for a given year

No. of people in state over age 65 in a given year (measured in 000)

State has Certificate of Need regulation for nursing home construction in a given year

State has moratorium on new nursing home construction in a given year

Western states: CA, NV, OR, WA

Great Lake states: IL, IN, MI, OH, WI

Mid-Atlantic states: DE, MD, NJ, NY, PA

Northeast states: CT, ME, MA, NH, RI, VT

Prairie states: IA, KS, MN, MO, NE, ND, SD

Rocky Mountain states: CO, ID, MT, UT, WY

Southeast states: AL, AR, FL, GA, KY, LA, MS, NC, SC, TN, VA, WV

Southwest states: AZ, NM, OK, TX of the facilities disappeared) and somewhat higher in 1996. Some disappearances reflect facilities that closed, particularly in the earlier years of the study period, although many cases of disappearance from the data are facilities with longer intervals between inspections (i.e., they will reappear in inspection reports subsequent to the study period). If closed facilities differ systematically from those that remain in the sample, this can result in sample selection bias due to attrition. This potential bias occurs because the data omit the final performance of missing facilities. To check for this possible sample selection bias, we estimated supplementary models using Heckman's (1979) two-stage-least-squares procedure. Our main findings did not change materially in these analyses, likely because there are few disappearances that appear to be closures.

2. The likelihood of acquisition across facilities owned by the same chain may correlate, in that the chain may divest several facilities at once, but sensitivity analyses examining acquisition for independent and chain-owned facilities separately found few differences.

3. Because we pool repeated observations on the same nursing homes, it is possible that the OLS assumption of independence from observation to observation is violated, and as a result that the model's residuals will be autocorrelated. First-order autocorrelation occurs when the disturbances in one time period are correlated with those in the previous time period, 
resulting in incorrect variance estimates. We checked for the presence of such autocorrelation using the Durbin-Watson statistic, and found none. Therefore, for simplicity, we present OLS regression estimates.

4. The quadratic relationship fits about as well as a logged value of the health quality variables, so that the results indicate a decreasing tendency to acquire homes as quality declines.

5. Figure 1 uses coefficients for Acquisition, Acquisition $\times$ Target problems, and Acquisition $\times$ Acquirer problems from columns 1 and 2 in Table 3 . The calculations start with target performance during the pre-acquisition period and then update target performance for each subsequent period, based on the prior period influences of target and chain performance. The calculations assume that chain performance remains unchanged since the pre-acquisition period.

\section{REFERENCES}

Aaronson WE, Zinn JS, Rosko MD. 1994. Do for-profit and not-for-profit nursing homes behave differently? The Gerontologist 34: 775-786.

Argote L, Ingram P. 2000. Knowledge transfer: a basis for competitive advantage in firms. Organizational Behavior and Human Decision Processes 82: 150-169.

Banaszak-Holl J, Zinn JS, Mor V. 1996. The impact of market and organizational characteristics on nursing care facility service innovation: a resource dependency perspective. Health Services Research 31: 97-109.

Barney JB. 1991. Firm resources and sustained competitive advantage. Journal of Management 17: 99-120.

Baum JAC. 1999. The rise of chain nursing homes in Ontario, 1971-1996. Social Forces 78: 543-584.

Baum JAC, Ingram P. 1998. Survival-enhancing learning in the Manhattan hotel industry, 1898-1990. Management Science 44: 996-1016.

Baum JAC, Li SX, Usher JM. 2000. Making the next move: how experiential and vicarious learning shape the locations of chains' acquisitions. Administrative Science Quarterly 45: 766-801.

Capron L. 1999. The long-term performance of horizontal acquisitions. Strategic Management Journal 20: 987-1018.

Capron L, Mitchell W. 1998. Bilateral resource redeployment and capabilities improvement following horizontal acquisitions. Industrial and Corporate Change 7: 453-484.

Capron L, Dussauge P, Mitchell W. 1998. Resource redeployment following horizontal acquisitions in Europe and North America, 1988-1992. Strategic Management Journal 19: 631-661.

Chatterjee S, Wernerfelt B. 1991. The link between resources and type of diversification: Theory and evidence. Strategic Management Journal 12: 33-48.

Cohen JW, Dubay LC. 1990. The effects of Medicaid reimbursement method and ownership on nursing home costs, case mix and staffing. Inquiry 27: 183-200.
Consumer Reports, 1995. Nursing homes-when a loved one needs care. August, 1995; p. 518-528.

Darr E, Argote L, Epple D. 1995. The acquisition, transfer and depreciation of knowledge in service organizations: Productivity in franchises. Management Science 41: 1750-1762.

Dranove DA, Shanley M. 1995. Cost reduction or reputation enhancement motives for mergers: the logic of multihospital systems. Strategic Management Journal 16: 55-74.

Dranove DA, Durkac A, Shanley M. 1996. Are multihospital systems more efficient? Health Affairs 15(1): 100-104.

Dutz MA. 1989. Horizontal mergers in declining industries: theory and evidence, International Journal of Industrial Organization 7: 11-33.

Epple D, Argote L, Murphy K. 1996. An empirical investigation of the microstructure of knowledge acquisition and transfer through learning by doing. Operations Research 44: 77-86.

Greve HR. 1999. Branch systems and nonlocal learning in organizational populations. In Advances in Strategic Management, Miner AS, Anderson PC. (eds). 16: 57-80.

Greve HR, Baum JAC. 2001. It's a multiunit, multimarket world. In Multiunit-Multimarket Strategy (Advances in Strategic Management, Volume 18), JAC Baum and HR. Greve (eds). JAI Press/Elsevier: Oxford UK; 1-28.

Hannan MT, Freeman J. 1984. Structural inertia and organizational change. American Sociological Review 49: 149-164.

Harrington C, Carillo H. 1999. The regulation and enforcement of federal nursing home standards, 1991-1997. Medical Care Research and Review 56(4): 471-494.

Harrington C, Swan JH, Wellin V, Clemena W, Carillo HM. 1999. 1998 State data book on long term care program and market characteristics. Research funded by the US Health Care Financing Administration and the US Department of Housing and Urban Development.

Harrington C, Woodhandler S, Mullan J, Carrillo H, Himmelstein D. 2001. Does investor ownership of nursing homes compromise the quality of care? American Journal of Public Health 91 (9): 1452-1455.

Holmes JS. 1996. The effects of ownership and ownership change on nursing home industry costs. Health Services Research 31: 327-346.

Huber GP. 1991. Organizational learning: the contributing processes and literatures. Organization Science 2: $88-115$.

Ingram P. 1996. Organizational form as a solution to the problem of credible commitment: the evolution of naming strategies among US hotel chains, 1896-1980. Strategic Management Journal 17 (Summer Special Issue): 85-98.

Ingram P, Baum JAC. 1997. Chain affiliation and the failure of Manhattan hotels, 1898-1980. Administrative Science Quarterly 42: 68-102.

Ingram P, Baum JAC. 2001. Interorganizational learning and the dynamics of chain relationships. In 
Multiunit-Multimarket Strategy (Advances in Strategic Management, Volume 18), Baum JAC, Greve HR. (eds). JAI Press/Elsevier: Oxford UK; 103-139.

Jensen MC. 1986. Agency costs of free cash flow, corporate finance, and takeover. American Economic Review: Papers and Proceedings 76: 323-329.

Jensen MC, Ruback R. 1983. The market for corporate control: the scientific evidence. Journal of Financial Economics 11: 5-50.

Karim S, Mitchell W. 2000. Reconfiguring business resources following acquisitions in the US medical sector, 1978-1995. Strategic Management Journal (Special Issue on the Evolution of Business Capabilities) 21 (10-11): 1061-1081.

Lemke S, Moos RH. 1989. Ownership and quality of care in residential facilities for the elderly. The Gerontologist 29: 209-215.

Light DW. 1986. Corporate medicine for profit. Scientific American 255: 38-45.

Marlin D, Sun M, Huonker JW. 1999. Strategic groups and performance in the nursing home industry: A reexamination. Medical Care Research and Review 56(2): 156-176.

McGinley L. 1999. Medicaid fix: House limits evictions from nursing homes. Wall Street Journal March 11: B1.

Mitchell W. 1994. The dynamics of evolving markets: the effects of business sales and age on dissolutions and divestitures. Administrative Science Quarterly 39: 575-602.

Mitchell W, Baum JAC, Banaszak-Holl J, Berta WB, Bowman D. 2002. Opportunity and constraint: chainto-component transfer learning in multiunit chains of U.S. nursing homes, 1991-1997. In Strategic Management of Intellectual Capital and Organizational Knowledge, Bontis N, Choo CW. (eds). Oxford University Press: Oxford, forthcoming.

Mueller DC. 1980. The Determinants and Effects of Mergers. Oelgeschlager Gunn, and Hain: Cambridge, MA.

Mukamel DB. 1997. Risk-adjusted outcome measures and quality of care in nursing homes. Medical Care 28(10): 952-962.

Nyman J, Bricker D. 1989. Profit incentives and technical efficiency in the production of nursing home care. Review of Economics and Statistics 71: 586-601.
Penrose E. 1959. The Theory of the Growth of the Firm. Wiley: New York.

Peteraf M. 1993. Cornerstones of competitive advantage: a resource-based view. Strategic Management Journal 14: 179-191.

Pfeffer J, Salancik GR. 1978. The External Control of Organizations. Harper \& Row: New York.

Ravenscraft DJ, Scherer FM. 1987. Mergers, Sell-offs, and Economic Efficiency. Brookings Institution: Washington, D.C.

Rosko MD, Chilingerian JA, Zinn JS, Aaronson WE. 1995. The effects of ownership, operating environment, and strategic choices on nursing home efficiency. Medical Care 33: 1001-1021.

Scherer FM, Ross D. 1990. Industrial Market Structure and Economic Performance (3rd edn). Houghton Mifflin: Boston, MA.

Scott RA, Aiken LH, Mechanic D, Moravcsik J. 1995. Organizational aspects of caring. The Milbank Quarterly 73 (1): 77-95.

Starr, Paul. 1982. The Social Transformation of American Medicine. New York: Basic Books.

Szulanski G. 1996. Exploring internal stickiness: impediments to the transfer of best practice within the firm. Strategic Management Journal 17: 27-43.

Tennyson DH, Fottler MD. 2000. Does system membership enhance financial performance in hospitals? Medical Care Research and Review 57 (1): 29-50.

Weisbrod BA, Schlesinger M. 1986. Public, private, nonprofit ownership and the response to asymmetric information: the case of nursing homes. In The Economics of Nonprofit Institutions: Studies in Structure and Policy, Rose-Ackerman S. (ed). Oxford University Press: New York, 133-151.

Wells R, Banaszak-Holl J. 2000. A critical review of market level health care strategy literature, 1991-1997. Social Science and Medicine 51: 639-656.

Wernerfelt B. 1984. A resource based-view of the firm. Strategic Management Journal 5:171-180.

Zinn JS. 1993. The influence of nurse wage differentials on nursing home staffing and resident care decisions. The Gerontologist 33(6): 721-729.

Zinn JS, Mor V, Castle N, Intrator O, Brannon D. 1999. Organizational and environmental factors associated with nursing home participation in managed care. Health Services Research 33(6): 1753-1767. 